\title{
Striga (Witchweed) Threats to Cereal Crops Production and Its Management: A Review
}

\author{
Nagassa Dechassa* Belay Abate \\ Ethiopian Institute of Agricultural Research, Ambo Agricultural Research Center, \\ P. O. Box 37, Ambo, Ethiopia
}

\begin{abstract}
Striga (witchweed) is one of the most successful parasitic weeds of cereal crops in Africa. It is 'a poor farmer's problem' as there is a near perfect ecological overlap between areas of Striga infestation and where hunger prevails. It is originated in Semien hills of Ethiopia and the Nubian hills of Sudan and later expanded in about 42 African countries. Striga hermonthica, Striga asiatica, Striga gesnerioides, and Striga aspera constitute the greatest economic threat to cereal crops' yield losses. They are obligate root parasites causing growth inhibition and yield losses of $20-100 \%$ in maize, rice, sorghum, pearl millet, finger millet, sugar cane and cowpea. Cultural practices such as long-term rotational cultivation of cereal crops with legume crops unaffected by the parasite is effective in managing the weed. Besides, biological control by use of parasitic fungi (Fusarium oxysporum and Vesicular arbuscular mycorrhiza) play a role in managing the weed. In addition, chemical control with imidazolinone herbicide, ethylene gas, dicamba and 2,4-D are effective in managing striga in cereal crops in extreme cases. Integrated use of striga resistant crop varieties with water conservation practices, soil fertility amendment and use of parasitic fungi (Fusarium oxysporum and Vesicular arbuscular mycorrhiza) is effective in control, economically safe, socially acceptable and environmentally friendly than a single control measure. Therefore, the promising integrated striga management practices should be highly promoted. Moreover, host and Striga species specific integrated Striga management should be designed.
\end{abstract}

Keywords: Haustoria; Obligate parasite; Root parasite; Strigolactones; Witchweed

DOI: $10.7176 /$ ALST/88-02

Publication date:July $31^{\text {st }} 2021$

\section{Introduction}

Parasitic weeds attack other plants by making networks and deriving portion or entire of their nourishment from their host. They are a major threat to native biodiversity, agricultural lands, range lands, national parks, road sides and urban green spaces with great economic and social consequences [1]. Up to a date about 4000 parasitic weeds are identified exploiting another plant vascular system to fulfill their nutrient requirements. Among these parasitic weed species $90 \%$ of them are hemiparasites retaining photosynthetic capacity while the rest, $10 \%$ of the species are holoparasites with obligate dependence on the host to obtain all their nutrients [2].

Some parasitic species have evolved to parasitize agricultural plants becoming weedy and posing a difficult-to-control threat to agriculture and cause serious problems for farmers in many parts of the world [3]. Root parasites (Striga spp. and Orobanche spp.) and shoot parasites (Cuscuta spp., Viscum spp. and Arceuthobium spp.) are the major threat to agriculture which cause the majority of yield losses [4]. If they are not timely managed, they can induce serious yield losses up to total failure of crop productivity [5].

Striga species from the family Scrophulariaceae [6] is one of the most important root parasites which causes serious threat to sorghum (Sorghum bicolor), maize (Zea mays), rice (Oryza sativa), pearl millet (Pennisetum glaucum), finger millet (Eleusine coracana), cowpea (Vigna unguiculata) and sugar cane (Saccharum officinarum) production in both tropical and sub-tropical countries in Africa [7]; [8]. Striga hermonthica, Striga asiatica, Striga gesnerioides, and Striga aspera constitute the greatest economic threat to cereal crops production and productivity [9]. The weeds are widespread with high rates of infestation across African countries. This is due to the fact that many farmers have limited knowledge about the weed and were therefore indifferent towards its control resulting in increasing weed infestation [10]; [11].

Continuous use of susceptible crop varieties without any protective measures causes disastrous levels of heavy infestation, crop failures and buildup of the Striga seed reserve in the soil. Considering the destructive effect of this weed infestation to cereal crops production, many studies have been conducted on its management [10]; [12]; [13]. It is also extremely difficult to achieve effective control of Striga spp. by a single control measure because of the nature of attachment and association between host and parasite requires a highly selective herbicide to destroy the parasite without crop damage. However, different management practices reducing the weed population and increasing crop yield are studied by different scholars. Therefore, the objective of this paper is to review the occurrences, distributions, economic importance and management practices of striga weed. 


\section{Body of the Text}

\subsection{Geographical Distribution, Species Diversity and Host Range of Striga}

Striga spp. are considered as 'a poor farmer's problem' because of the fact that there is a near perfect ecological overlap between areas of Striga infestation and where the poor farm and where hunger prevails [10]. Semien hills of Ethiopia and the Nubian hills of Sudan is believed to be the center of origin for diversity of Striga species [14]. The striga species later expanded to about 42 countries in Africa [10]; [15]. These dispersal events are agricultural in origin with the transport of contaminated crop seed or via livestock.

African countries such as Ethiopia, Somalia, Kenya, Tanzania, South Sudan, Sudan, Eretria, Chad, Cameroon, Niger, Nigeria, Burkina Faso, Mali, Senegal, Gambia, Malawi, Mozambique and Botswana are heavily infested by Striga spp. Whereas moderate infestations by the striga spp. are reported in Benin, Burundi, Ghana, Uganda, Congo, Central African Republic, Liberia, Democratic republic of congo, Zambia, Sierra Leon, Gunnie, Gunnie Bissau and Mauritania. However, light weed infestations are reported from Western Sahara, Djibouti, Egypt, South Africa, Namibia, Angola, Congo Republic, Gabon, Equatorial Guinea, Swaziland and Lesotho (Figure 1) [10]; [15].

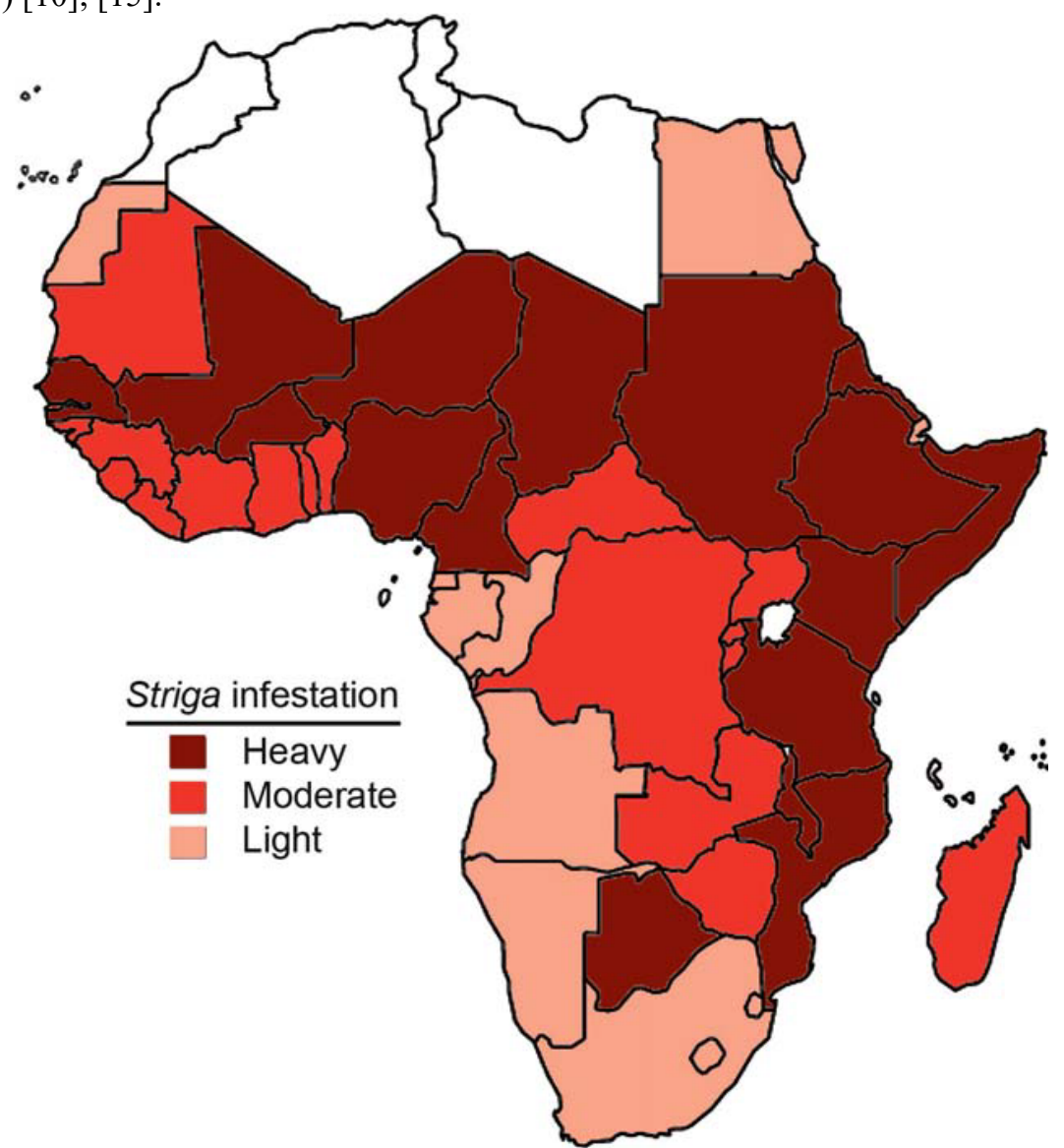

Figure 1. Striga distribution and infestation in African countries (Source: [10])

The genus Striga comprises more than 40 species, of which 11 species are considered parasitic on many cereals and few pulses [16]. Locally adapted Striga races have long been observed that specialize on particular crops [9]. Several factors contribute to genetic diversity in Striga: (i) seeds can persistent in the soil for many generations; (ii) hybridization; (iii) wide geographic dispersals; and (iv) locally adapted host races.

Striga species are considered as a wide spreading and having wide hosts range, which are extremely difficult to control and result in significant economic losses [17]; [18]; [19]. They are reported by several workers occurring in mild to severe form on a variety of hosts. Cereal crops (Maize, rice, sorghum, pearl millet, finger millet, sugar cane) and pulse crop (cowpea) are generally the preferred hosts of this parasitic flowering species [18]; [19]; [20].

Striga hermonthica expanded throughout Eastern Africa in Kenya, Uganda, Tanzania, Ethiopia, Sudan, Rwanda, and Burundi as well as in West Africa in Niger, Nigeria, Libya, Chad, Western Sahara, Guinea, Burkina Faso, and Mali parasitizing maize, millet, sorghum, and upland rice (Figure 2). Striga asiatica occurs in both Southern and Eastern Africa, the Arabian Peninsula, India, and Pakistan parasitizing rice, sorghum, and millet. Whereas Striga gesnerioides infects dicotyledonous plants, greatly limiting cowpea production in the West African countries of Mali, Burkina Faso, Niger, and Benin. Striga aspera constrains maize and rice 
production in Sudan, Malawi, Nigeria, Cameroon, Ivory Coast, and Senegal [21].
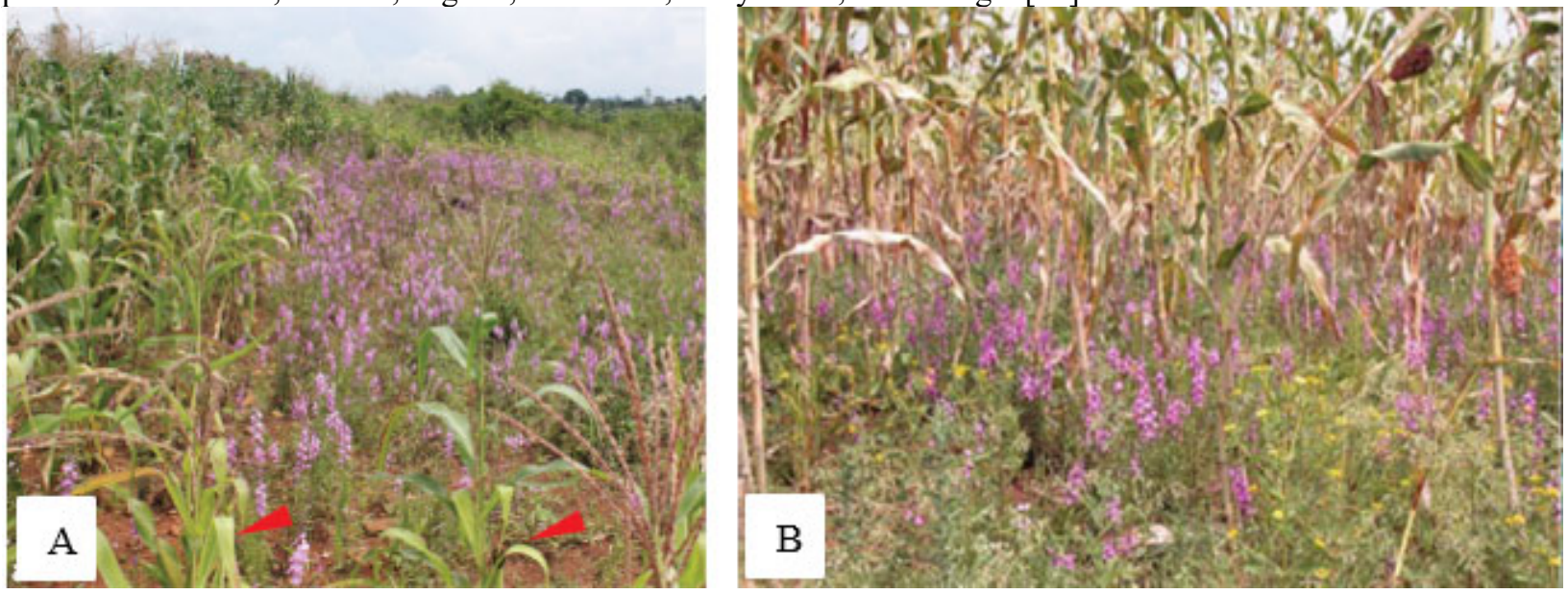

Figure 2. Destructive effect of Striga hermonthica on: A) Maize B) Sorghum

\subsection{Unique Characteristics of Striga}

Many unique characteristics of Striga are indicative of a successful parasitic weed whose control should take into account biological and chemical mechanisms underpinning Striga-host interaction. Striga reprograms the host in ways that are beneficial to its parasitism.

The unique characteristics of striga are; (i) the striga genus has many species that are widely distributed each with different host preferences, (ii) the ability to produce large number of seeds 50000 to 500000 per plant, (iii) its seed persistence in the soil for long period of time 15-20 years, (iv) seed dispersal mechanism, (v) Striga life cycle is highly synchronized with its host plants, (vi) its ability to alter levels of important hormone such as abscisic acid, cytokinins, and gibberellic acid during infection [22] (vii) it acquire genes from its host and modify them for parasite use [23], (viii) it is a sophisticated manipulator of host immunity [24], and (ix) it is able to subdue host defense by producing a series of effectors, just like bacterial and fungal pathogens.

\subsection{Ways of Striga Mobility}

Small sized Striga seed greatly enhances the parasite's dispersal by wind, water, and contaminated crop seeds. It also adheres to persons and animals, further aiding in seed spread and contamination of uninfected fields. However, a small Striga seed size means that the endosperm can only support growth for three to seven days [25]. Therefore, the seed germination must be rapid and synchronized with host localization.

\subsection{Requirements for Striga Growth and Development}

The growth and development of striga is highly associated to the host plant and physical environment. The Striga seeds germination is dependent the exudates released by host roots plants. Striga spp. thrive low soil fertility, light sandy soils, nutrient depleted soils with low organic matter content, low rainfall areas and temperature ranges of 18 to $40^{\circ} \mathrm{C}[26]$.

\subsection{Life Cycle of Striga and Mechanism of Host Infection}

The life cycle of Striga is highly synchronized with its host. It encompasses three general phases (germination, haustorium formation, and penetration (Figure 3a-c and Figure 4). Seed germination initiated only in the presence of a susceptible host, which Striga locates using plant hormones called strigolactones. Following Striga seed germination, the Striga radicle attaches to the host and differentiates into a specialized organ called the haustorium (Figure 3b and c) [27]. The haustorium develops in response to chemical signals from the host, the haustorial inducing factors such as 2,6-dimethoxy-p-benzoquinone [28]. Finally, the haustorium of Striga penetrates the hosts root until it encounters the endodermis, where haustorial cells elongate and divide to establish vascular connections with the host plants (Figure $3 b$ and c) [25]. Once the vascular systems of the host and parasite are connected, Striga uses this connection to siphon out nutrients[25]. 

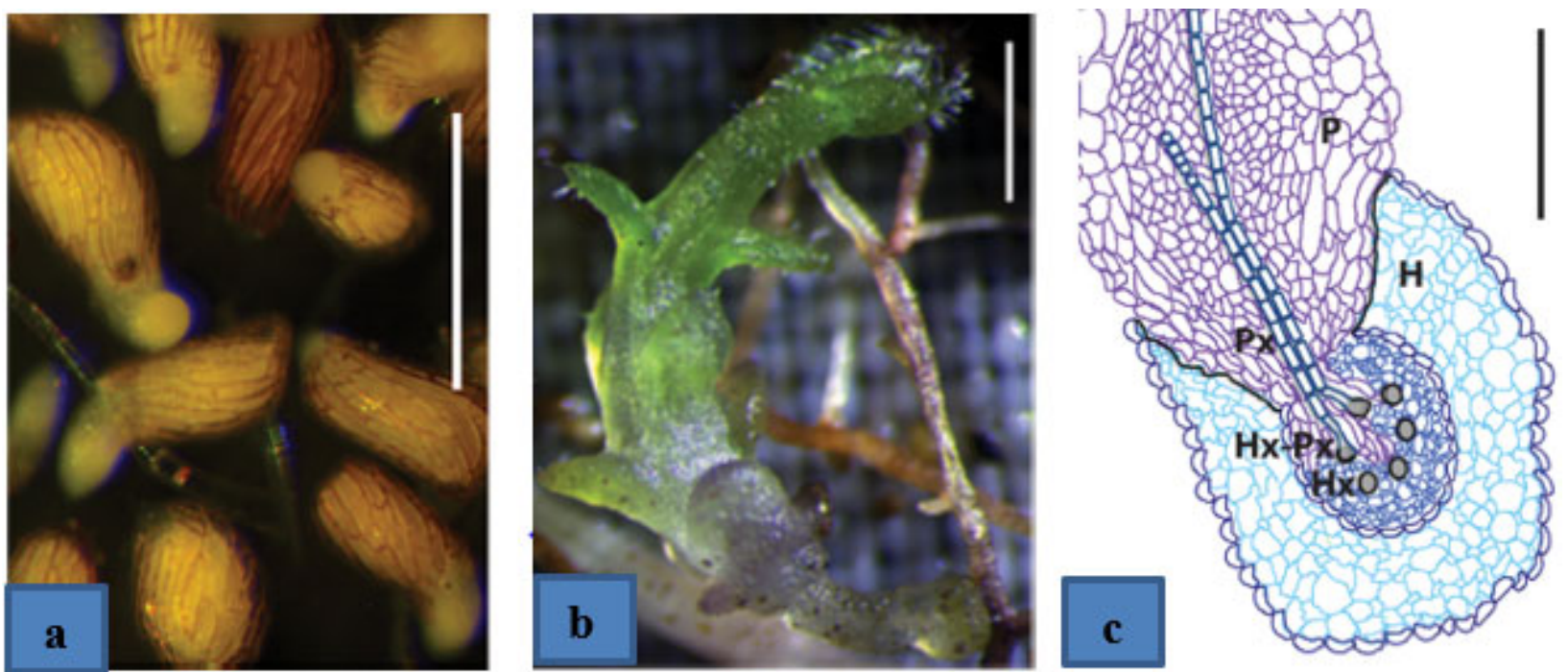

Figure 3. Striga at a glance. (a) Striga seedlings 12 hours after treating with a germination stimulant (GR24). Scale bar $=0.5 \mathrm{~mm}$. (b) A 10-day old Striga seedling with a well-developed haustorium attached to a sorghum root. Scale bar $=0.2 \mathrm{~mm}$. (c) A schematic of a section through a 10-day old Striga seedling showing the parasite (P) attached to a host (H). By this time, the parasite has developed fully. The parasite xylem (Px) has merged with the host xylem $(\mathrm{Hx})$ to form a siphon $(\mathrm{Hx}-\mathrm{Px})$ that sucks out nutrients from the host. Scale bar $=0.05 \mathrm{~mm}$. ICRISAT, International Crops Research Institute for the Semi-Arid Tropics

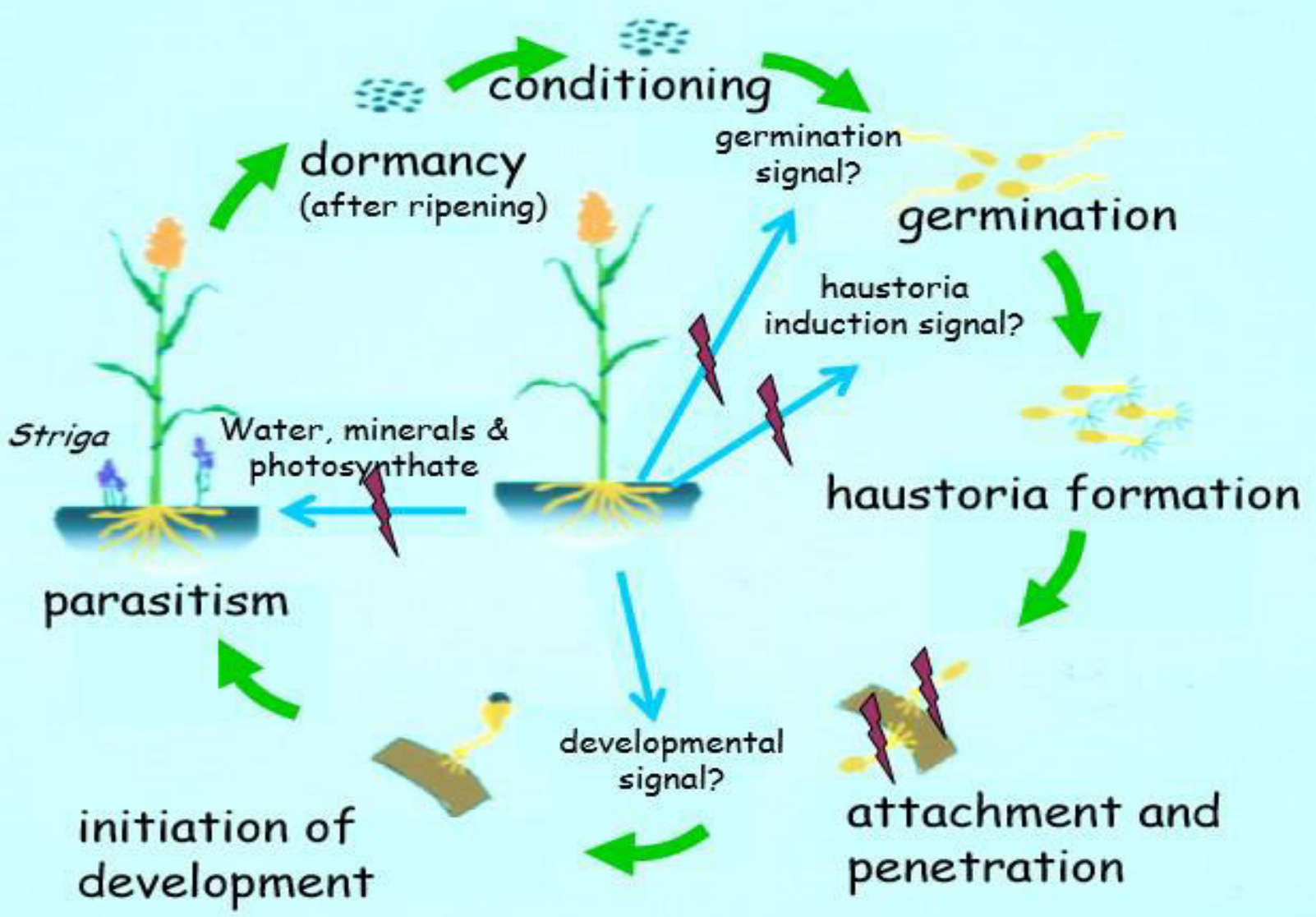

Figure 4: Illustrated Striga life cycle (Source:- [29])

2.6. Economic Importance of Striga species

Striga hermonthica, S. asiatica, S. gesnerioides, and S. aspera seriously affect cereals in many African countries. 
They are obligate root parasites causing growth inhibition and yield losses of many cereal crops [13]; [18]; [19]; [30].

The wide host range of striga spp and their wide geographical distribution, make them amongst the most damaging parasitic weeds [30]. Studies indicated that Striga hermonthica infestation reduced Maize, rice, sorghum, pearl millet, finger millet, sugar cane yield by 30 to 90\%; Striga asiatica and Striga forbesii reduced maize yield by $30-90 \%$ in Tanzania [30]. In Kenya, these species infestation reduced maize, rice, sorghum, pearl millet and finger millet yield by 15 to $100 \%$ [18, 31]. Striga hermonthica and Striga asiatica infestation reduced sorghum, millet and Maize yield by 60 to 100\% in Uganda [18]. Striga hermonthica infestation reduced sorghum yield by 58 to $100 \%$ in Ethiopia and Sudan [13]; [19].

\subsection{Managements of Striga}

Striga has been known in many cereal crops in many African countries for many years [10]; [12]; [30] and many studies have been conducted on its management since the potential threat of the weed to cereal crops production [10]; [12]; [13]. The weed is widespread on many crops with high rates of infestation across African countries. This is due to the fact that many farmers have limited knowledge about the weed and were therefore indifferent towards its control resulting in increasing weed infestation [10]; [32]. It is also extremely difficult to achieve effective control of Striga by a single control measure because of the nature of attachment and association between host and parasite requires a highly selective herbicide to destroy the parasite without crop damage. However, different management practices reducing the weed population and increasing crop yield are studied by many intellectuals.

\subsubsection{Host resistance}

The use of host resistant varieties reduces the yield losses caused by Striga spp. by lowering the production of germination stimulant, being mechanical barriers between the parasite and host, inhibition of germ tube exoenzymes, phytoalexins synthesis, incompatibility, antibiosis, insensitivity to striga toxin and avoidance [10]; [13]; [17]. However, poor adoption for some resistant varieties, incompatibility of some genotypes and resistance break down observed in some host verities are a big challenge in the control of striga by the use of host resistance [12].

\subsubsection{Striga Seedbank Depletion}

Application of simple chemical synthesis of strigolactones play a crucial role in significantly reducing Striga seeds in the soil. Chemical molecules that mimic the activity of strigolactones can cause the parasite to germinate in the absence of a host. This strategy is known as suicidal germination [21]. Even though this technology was previously not feasible due to the high cost of multistep chemical synthesis of strigolactones and its instability under field conditions, currently it is possible to synthesize simple strigolactone analogues that when treated with chemical formulations, retain activity and stability under field conditions [21].

\subsubsection{Striga Management by Herbicides}

The damage caused to the crops by root parasitic weeds can be reduced by using herbicides [33]; [34]. Seed coating of cowpea with an imidazolinone herbicide, imazaquin, is effective in reducing the populations of $S$. gesnerioides and Alectra vogelii attached to cowpea [34]. However, high-dose of imizaquin reduced the germination rate and delayed the flowering in cowpea [34]. Eplee [35] also concluded that ethylene gas used as a germination stimulant in the suicidal germination strategy successfully eradicated S. asiatica. Another study also indicated that dicamba and 2,4-D are used as feasible herbicides in controlling $S$. asiatica in the early program in United States and African countries [33]. However, the herbicides themselves can cause the problem by damaging a part or the whole plant parts since there is no selective herbicide for root parasitic weeds [34].

\subsubsection{Striga Management by Cultural Practices}

The best practice is long term rotational cultivation of cereal crops with legumes or other crops unaffected by the parasite. Cultural practices such as crop rotation, water management, early planting and use of early maturing varieties are effective in reducing striga seed banks in the soil, improving soil fertility, enhancing sorghum growth rate and retarding the parasites seed germination and seedling development [36]. However, their poor adoption, high cost of implementation, high labor requirement and inapplicability of them on large fields are limitation of cultural striga management practices [36].

\subsubsection{Striga Management by Biological Control Agents}

Biological control by using Fusarium oxysporum f.sp. strigae (FOS) is effective in controlling striga spp. The use of Fusarium oxysporum in controlling striga has many advantages: i) it has no residual effect, ii) it Reduces Striga population below its threshold level, iii) it improves sorghum yield and reduces days to maturity in sorghum. However, it not yet developed commercially for Striga management in most countries [13]; [17]; [37]. Vesicular arbuscular mycorrhizal (VAM) fungi are also reported to control Striga and enhance biomass production of compatible hosts when integrated with resistance genes [38].

\subsubsection{Integrated Striga Management}

No any single solution is likely to offer long-lasting solution to the serious problem of parasitic weeds. 
Integration of striga resistant sorghum varieties (Gobiye, Abshir, Birhan, Hormat, and Gedo) with water conservation practices using tie-ridges and soil fertility amendment by optimum rates of inorganic fertilizers (UREA and DAP) plays a crucial role in striga management in sorghum [32]. Ejeta, [39] also concluded that integration of resistant cultivars with application of optimum rate of chemical fertilizer and soil moisture conservation using tied ridges significantly increased grain yield by reducing infestation by Striga. Also, the use of resistant sorghum genotypes that are compatible with FOS and VAM, biocontrol agents of Striga, together with host plant resistance could promote integrated Striga management (ISM). An ISM strategy that combines the use of Striga resistant crop varieties compatible with FOS is cost effective, environmentally friendly and can easily be adopted by smallholder farmers [36]; [40]. However, ISM is yet to be commercialized in many sorghum producing countries. Correspondingly the sequential application of pre-emergence herbicide (Dual gold) and post emergence herbicide (2, 4-D) is effective against Striga weed in sorghum in Ethiopia [41].

\section{Conclusions}

Striga spp. are among serious parasitic weeds of cereal and pulse crops in many countries of Africa. They are root holoparasites and rely on host plants to complete their life cycle. Striga hermonthica, Striga asiatica, Striga gesnerioides, and Striga aspera are the most wide spreading among 40 Striga species. Maize, rice, sorghum, pearl millet, finger millet, sugar cane and cowpea are hosts for Striga spp. They cause drastic crop yield losses. The Striga seed persistence in the soil for long period of time, the ability to produce large number of seeds per plant, ability to adapt to wide range of climatic conditions, its high synchronization with host plants, nature of attachment to the hosts and association between host and parasite made their management difficulty.

However, cultural practices such as long-term rotational cultivation of cereal crops with legumes or other crops unaffected by the parasite is effective in managing the weed. Besides, biological control by use of parasitic fungi (Fusarium oxysporum and Vesicular arbuscular mycorrhiza) play a role in managing the weed. In addition, chemical control with imidazolinone herbicide (imazaquin), ethylene gas dicamba and 2,4-D are effective to control striga in cereal crops in extreme cases. Integrated use of striga resistant host varieties with water conservation practices using tie-ridges and soil fertility amendment and use of parasitic fungi (Fusarium oxysporum and Vesicular arbuscular mycorrhiza is effective in control, economically safe, socially acceptable and environmentally friendly than a single control measure.

\section{The Way Forward}

Since the current status of Striga is remarkably on increasing trend, it is recommended to: -

1) Create awareness in the community about the threat and management options of the weed.

2) Detect and monitor early since they are critical for the management of striga, as successful eradication is only possible when infestations are small.

3) Search for more improved or alternative approaches in managing the weed.

4) Promote Integrated Striga Managements such as;

a). Integration of striga resistant sorghum varieties (Gobiye, Abshir, Birhan, Hormat, and Gedo) with tieridges water conservation and soil fertility amendment

b). Integration of resistant host genotypes that are compatible with biocontrol agents (FOS and VAM)

\section{References}

1. Press, M.C. and G.K. Phoenix, Impacts of parasitic plants on natural communities. New phytologist, 2005. 166(3): p. 737-751.

2. Rubiales, D. and M. Fernández-Aparicio, Innovations in parasitic weeds management in legume crops. A review. Agronomy for Sustainable Development, 2012. 32(2): p. 433-449.

3. Parker, C., The parasitic weeds of the Orobanchaceae, in Parasitic Orobanchaceae. 2013, Springer. p. $313-$ 344.

4. Sarić-Krsmanović, M., et al., Infestation of Field Dodder (Cuscuta campestris Yunck.) Promotes Changes in Host Dry Weight and Essential Oil Production in Two Aromatic Plants, Peppermint and Chamomile. Plants, 2020. 9(10): p. 1286

5. Samejima, H. and Y. Sugimoto, Recent research progress in combatting root parasitic weeds. Biotechnology \& Biotechnological Equipment, 2018. 32(2): p. 221-240.

6. Botanga, C.J., et al., Genetic variability of Striga asiatica (L.) Kuntz based on AFLP analysis and hostparasite interaction. Euphytica, 2002. 128(3): p. 375-388.

7. Haruna, P., et al., Farmers and Agricultural Extension Officers Perception of Striga gesnerioides (Willd.) Vatke Parasitism on Cowpea in the Upper East Region of Ghana. Advances in Agriculture, 2018. 2018.

8. Joel, D.M., The long-term approach to parasitic weeds control: manipulation of specific developmental mechanisms of the parasite. Crop Protection, 2000. 19(8-10): p. 753-758. 
9. Mohamed, K.I., et al., Genetic diversity of Striga and implications for control and modeling future distributions, in Integrating new technologies for striga control: towards ending the witch-hunt. 2007, World Scientific. p. 71-84.

10. Ejeta, G. and J. Gressel, Integrating new technologies for Striga control: towards ending the witch-hunt. 2007: World Scientific.

11. Ejeta, G. and T. Tessema, SORGHUM PRODUCTION IN TRANSITION Through Striga Management. 2019.

12. Mrema, E., et al., Screening of sorghum genotypes for resistance to Striga hermonthica and S. asiatica and compatibility with Fusarium oxysporum f. sp. strigae. Acta Agriculturae Scandinavica, Section B-Soil \& Plant Science, 2017. 67(5): p. 395-404.

13. Mrema, E., et al., Farmers' perceptions of sorghum production constraints and Striga control practices in semi-arid areas of Tanzania. International Journal of Pest Management, 2017. 63(2): p. 146-156.

14. Atera, E.A., et al., Striga infestation in Kenya: status, distribution and management options. 2013.

15. AGT, B., Striga: The spreading scourge in Africa. Regulation of Plant Growth \& Development, 2007. 42(1): p. 74-87.

16. Ejeta, G., The Striga scourge in Africa: a growing pandemic, in Integrating new technologies for Striga control: towards ending the witch-hunt. 2007, World Scientific. p. 3-16.

17. Mrema, E., et al., Integrated management of'Striga hermonthica'and'S. asiatica'in sorghum: A review. Australian Journal of Crop Science, 2020. 14(1): p. 36-45.

18. Gethi, J., et al., Genetic diversity of Striga hermonthica and Striga asiatica populations in Kenya. Weed Research, 2005. 45(1): p. 64-73.

19. Tesso, T., et al., An integrated Striga management option offers effective control of Striga in Ethiopia, in Integrating New Technologies for Striga Control: Towards Ending the Witch-Hunt. 2007, World Scientific. p. 199-212.

20. Asodewine, P.A., Effects of Pearl Millet (Pennisetum glaucum L.) and Cowpea (Vigna unguiculata L.) Intercrop on Striga hermonthica (Del.) Benth, Yield Components and Grain Yield in the Sudan Savannah Zone of Ghana. 2020.

21. Kountche, B.A., et al., Suicidal germination as a control strategy for Striga hermonthica (Benth.) in smallholder farms of sub-Saharan Africa. Plants, People, Planet, 2019. 1(2): p. 107-118.

22. Frost, D., et al., Striga hermonthica reduces photosynthesis in sorghum: the importance of stomatal limitations and a potential role for ABA? Plant, Cell \& Environment, 1997. 20(4): p. 483-492.

23. Yoshida, S., et al., Genome sequence of Striga asiatica provides insight into the evolution of plant parasitism. Current Biology, 2019. 29(18): p. 3041-3052. e4.

24. Saucet, S.B. and K. Shirasu, Molecular parasitic plant-host interactions. PLoS pathogens, 2016. 12(12): p. e1005978.

25. Runo, S. and E.K. Kuria, Habits of a highly successful cereal killer, Striga. PLoS pathogens, 2018. 14(1): p. e1006731.

26. Yoshikawa, F., et al., Biochemical requirements for seed germination and shoot development of witchweed (Striga asiatica). Weed Science, 1978: p. 119-122.

27. Yoshida, S., et al., The haustorium, a specialized invasive organ in parasitic plants. Annual review of plant biology, 2016. 67: p. 643-667.

28. Albrecht, H., J.I. Yoder, and D.A. Phillips, Flavonoids Promote Haustoria Formation in the Root ParasiteTriphysaria versicolor. Plant Physiology, 1999. 119(2): p. 585-592.

29. Ejeta, G. and L. Butler, Host-parasite interactions throughout the Striga life cycle, and their contributions to Striga resistance. African Crop Science Journal, 1993. 1(2).

30. Mrema, E., et al., Genetic analysis of the maximum germination distance of Striga under Fusarium oxysporum f. sp. strigae biocontrol in sorghum. Journal of Integrative Agriculture, 2018. 17(7): p. 15851593.

31. Mohamed, K.I. and L.J. Musselman, Taxonomy of agronomically important Striga and Orobanche species. Progress on farmer training in parasitic weed management, 2008. 41(3): p. 7-14.

32. Tessema, T. and G. Ejeta, Sorghum Production in Transition Through Striga Management. 2019.

33. Aly, R., Conventional and biotechnological approaches for control of parasitic weeds. In Vitro Cellular \& Developmental Biology-Plant, 2007. 43(4): p. 304-317.

34. Eizenberg, H., et al., Chemical control, in Parasitic Orobanchaceae. 2013, Springer. p. 415-432.

35. Parker, C., Protection of crops against parasitic weeds. Crop protection, 1991. 10(1): p. 6-22.

36. Jamil, M., B.A. Kountche, and S. Al-Babili, Current progress in Striga management. Plant physiology, 2021. 185(4): p. 1339-1352.

37. Sauerborn, J., D. Müller-Stöver, and J. Hershenhorn, The role of biological control in managing parasitic weeds. Crop protection, 2007. 26(3): p. 246-254.

38. Franke, A., et al., Evaluating and scaling-up integrated Striga hermonthica control technologies among 
farmers in northern Nigeria. Crop protection, 2006. 25(8): p. 868-878.

39. Ejeta, G., Breeding for Striga resistance in sorghum: exploitation of an intricate host-parasite biology. Crop Science, 2007. 47: p. S-216-S-227.

40. Hearne, S.J., Control-the Striga conundrum. Pest Management Science: formerly Pesticide Science, 2009. 65(5): p. 603-614.

41. Ayana, G., et al., Results of Plant Protection Research 2018. 2020, Ethiopian Institute of Agricultural Research. 